\title{
Moderating Effect of Marital Status among Mindfulness, Procrastination and Job Performance of Employees
}

\author{
${ }^{a}$ Malik Mureed Hussain, ${ }^{b}$ Zafar Ahmad \\ ${ }^{a}$ Multan Postgraduate College, Multan, Pakistan \\ Email:mpgclion@yahoo.com \\ ${ }^{\mathrm{b}}$ National University of Modern Languages, Islamabad, Pakistan \\ Email:zafarahmad@gmail.com
}

\begin{tabular}{l}
\hline ARTICLE DETAILS \\
\hline History: \\
Accepted 13 March 2021 \\
Available Online March 2021 \\
Keywords: \\
Mindfulness, Procrastination, Job \\
Performance, Marital Status
\end{tabular}

JEL Classification:

J28, J29

DOI: $10.47067 /$ real.v4i1.118

\begin{abstract}
Self-determination theory and job resource demand model is widely applied framework to understand mindfulness, procrastination and job performance of employees in organizational settings. The endeavor of the current research is to understand the moderating role of marital status among mindfulness, procrastination and job performance. Performance is behavior and is closely related to productivity in an organization. Although, job performance have several determinants where cognitive or mental ability is one of the determinants of job performance (Schmitt \& Hunter, 2004). Purposive sampling technique was applied based on cross sectional approach. Mindfulness attention awareness scale (MAAS; Brown \& Ryan, 2003) Tuckman's procrastination scale (TPS; Tuckman, 1991) and job performance scale (JPS; Wright, Kacmar, Mcmahan \& Deleeuw, 1995) were used on the sample of 400 employees working in telecom organizations. The correlation as well as moderation analysis were carried out to investigate the study data. Findings demonstrate the relationship of mindfulness, procrastination and job performance whereas marital status is performing moderating role among study variables. The results support the self-determination theory and job resource demand model.
\end{abstract}

(C) 2021 The authors. Published by SPCRD Global Publishing. This is an open access article under the Creative Commons AttributionNonCommercial 4.0

Corresponding author's email address: zafarahmad@gmail.com

\section{Introduction}

Organizations face significant loss due to distraction effecting job performances of employees. This poses a question to explore the role of procrastination and how is it counter-dealt by mindfulness. Mindfulness helps to perform routine task more attentively in efficient and effective manner, regarded as consciously paying attention which indicate attentiveness of mind (Bodhi, 2000) had constructive effect on the job performance in organization. Prior studies demonstrate the characteristics of mindfulness and mental health are linked with each other (Brown \& Ryan, 2003; Cheung \& Ng, 2018), achievement oriented self-regulation (Howell \& Buro, 2010), self-consciousness (Evans, Baer, \& 
Segerstrom, 2009), and procrastination (Flett et al., 2016).

Mindfulness improve executive functioning (Gallant 2016) job performance (Dane \& Bogels, 2014) increase number of contact hours at work (De Brium, Formsina, Frijsten \& Bogels, 2017) overcome stress at work, improve job satisfaction and performance (Shonim, Van Gordon, Dunn, Singh \& Griffiths, 2014) decreased stress, anxiety, depression, fatigue and negative effect (Gregoire \& Lachana; 2015). It reduces stress, fatigue and psychological distress (Huang, Li, Huang \& Tang 2015) and help to improve community functioning and life excellence (Bartlett, Lovell, Otahal, \& Sanderson, 2017).

Procrastination prevails a contradiction ground in previous research. long-term procrastination is enveloping above 20\% (Ferrari, O'Callaghan, \& Newbegin, 2005), creates depression, anxiety, stress, job performance and lower life satisfaction (Beheshtifar, Hoseinifar, \& Moghadam, 2011; Vaculík, Vytásková, Procházka, \& Zalis, 2016; Chun Chu \& Choi, 2005; Flett, Haghbin, \& Pychyl, 2016; Gagnon, Dionne, \& Pychyl, 2016; Richardson, Abraham, \& Bond, 2012), everyone defers to higher degree, particularly in organizations (Schouwenburg, Lay, Pychyl, \& Ferrari, 2004; Nguyen, Steel, \& Ferrari, 2013). It is categorized as a lack of self-control as well as self-regulation, and a predisposition to deliberately postpone indisputable everyday jobs (Gagnon et al., 2016; İskender, 2011; Sirois \& Tosti, 2012; Van Eerde, 2000). Procrastinators usually choose instant mood proclamation and avoid goals in support of more pleasurable tasks (Van Eerde, 200o).

Job performance is valued added behaviors acknowledged by organizations which create accomplishment of significant organizational goals (Campbell, 1991). It is an anticipated weightage of employees behavior performed during certain time frame (Motowidlo, Borman \& Schmidt, 1997). Job Performance behavior assessed indirectly (e.g; decision making), measured autonomously by consequences. According to Rotundo \& Sackett (2002) job performance is contextualized in terms of how an employee is performing on tasks, overall scenarios and counterproductive behaviors.

\section{Objectives}

- To investigate the association between mindfulness, procrastination and job performance among male and female employees.

- To study the moderating role of marital status in relation between mindfulness, procrastination and job performance.

\section{Hypotheses}

- There is a positive relationship between Mindfulness and job performance among study participants.

- The marital status impairs the relationship between mindfulness, procrastination and job performance.

\section{Theoretical Perspective}

Self-determination theory (Ryan \& Deci 1985) explains that humans are vigorous and dynamic creature while growth, challenges and seeking new experiences with sense of self. The theory focuses on social and cultural factors facilitation or challenge individuals' sense of imitation to their well-being and quality of performance. Individuals' autonomy, competence and relatedness are discussed for motivation and engagement of activities like performance, persistence and creativity.

Self-determination theory includes basic phenomenon that is eudemonic living and consider as basis for vigorous and effective self-regulation as mindfulness is strongly related to self- 
regulation. It is established in this theory that an open awareness regards for consciousness of present moment (Brown \& Ryan, 2003).

The Job Demands-Resources (JD-R) model emphasized on employee issues related to burnout, engagement and subsequently organizational performance (Bakker \& Demerouti, 2007; Demerouti et al., 2001). The model highlighted the supposition that companies and organizations have their own issues and factors of well-being categorized as job demands and resources. Job demands factors include heavy workload, stressful working environment, role ambiguity and poor relationships. Job resources factors include physical, societal or structural factors that assist in goal achievement and stress reduction. These factors also comprised of autonomy, work relationships, chances for progress, and training, mentoring and learning opportunities.

The model gave a comprehensive approach applicable for different occupations. Research gave indication for presence of two concurrent methods. High job demands consumed energies which lead exhaustion and impair mental and physical health. Apart from this, job resources are the motivational processes which foster employee involvement and performance at workplace. Numerous researched have found that job resources act like shield to control influences of job demands on stress-reactions. Research findings also suggested that job resources have potential to motivate specially with high job demand scenarios and help to enhance performance of employees at work. It is very obvious that when employee have resources (colleagues' support or having ability to one's own work) they tried to work beyond routine and focuses on goals and targets to accomplish (Wrzesniewski \& Dutton, 2001) on the other hand when employees having less resources at job additional performance related with their role suffer badly.

\section{Literature Review}

According to Morrison and Jha (2011), human mind depend on a set of cognitive processes (i.e. attention \& working memory) to guide moment-to-moment experience. Interest in cognitive training reveals that the cognitive processes are capacity limitations and are reduced in stress or negative affect. Mindfulness is mental attention to the existing moment without emotional reactions or conceptual engagement.

Klatt, Wise and Fish (2012) endorsed that Mindfulness at the workplace are becoming increasingly popular and may be provided by occupational stakeholders in an attempt to sustain a healthy workforce. Similarly, mindfulness training positively effects working memory to process information with multifaceted visual stimuli in an experiment in which participants were tested before and after participation and found that mindfulness training increases their performance (Vugt \& Jha, 2011).

Mindfulness among employees overcome psychological distresses which results in employee satisfaction and internal clientele significantly increased over the period of time (Grégoire \& Lachance, 2015). Howell and Buro (2010) explored that mindfulness was mediated by greater selfregulation over achievement. Mindfulness and effective self-regulation improve the well-being. Dane and Brummel (2014) stated positive association in mindfulness and job performance whereas inverse relationship in mindfulness and turnover intention at workplace.

Klingsieck's (2013) study evaluated that procrastination discrepancy in different life domains like education, job, routine activities and responsibilities, health, leisure, family matters, partnership and social relations. Deterioration in efficiency and performance was found nearly in all 
domains. Herweg and Muller (2011) examined that issues of self-control may minimize performance and well-being, effectively curtails the chances of procrastination, efficient workload structures which leads to improved job performance.

However, the constrained investigation led on this range reliably demonstrates that married employees are happier in jobs or works than single colleagues (Feldman, 1988). The cause might be that marriage stipulates expanded duties that may enable through solid employment, more profitable job. Positive relationship between marital status and quality of life whereas gender effect this relationship (Kyu-Tae Han, Eun-Cheol Park, Jae-Hyun Kim, Sun Jung Kim \& Sohee Park; 2014). Previous researches found the effect of marital status on job satisfaction few researches indicates that job satisfaction of married employees are higher than their unmarried colleagues (Austrom et. al. 1988; Federico et. al. 1976; Garrison and Muchinsky 1977; Watson 1981). The possible explanation could be that marriage and responsibility are linked with each other whereas job satisfaction is needing stable job. It has also been found that married respondents reported higher procrastination (independent of number of children) than employees currently married or single (jesse Harriott, Joseph R.Ferrari;1996). Single employee perform better than married employees as their commitment towards their family and other circumstances are considerably less when compared to the married employees (Lekha Padmanabhan1 \& Dr. R. Magesh; 2016)

Employees are valuable asset and important resource for an organization. Employees' development and efficiency issues can't be neglected. The spiritual side which focuses on mindfulness of an individual is an important factor (Osvat, 2013; Penman, \& Williams, 2011; Schaufenbuel, 2014). Procrastination of employees is another notable issue which is decreasing employee as well as organizational performance (Hammer \& Ferrari, 2002; Klatt, Wise \&Fish, 2012; Klingsieck, 2013; Morrison \& Jha, 2011; Vugt, \& Jha, 2011).

In Pakistan most of research work on mindfulness, procrastination and performance is being done on the discipline of academia and education focusing on academic procrastination and academic performance of students at college or university level (Hussain \& Sultan; 2010, Khan, Arif, Noor \& Muneer; 2014, Saleem, Bashir, Amin \& Noor; 2016, Zahra \& Riaz; 2017, Afzal \& Jami; 2018, Zubair, Kamal, Artemeva; 2018), while organizational context needs attention. After reviewing literature, a major gap with reference to mindfulness, procrastination and performance is identified this needs to be address in organizational setup.

The present research was meant to explore mindfulness, procrastination and job performance among employees in organizations related to the telecom employees whereas marital status of an employee has vital role as well. It was focused that mindfulness has positive association with job performance and negative association with procrastination, similarly procrastination has negative relation with job performance as well with the thought that once an employee or individual have more mindfulness and less procrastinating tendencies then it is more likely that he/she might be able to perform the maximum and produce the higher and expected results for the organization.

\section{Methodology}

The sample comprised of 400 employees (Male $=305$ and Female $=95$, Permanent $=213$ and Contractual $=187$, Public $=71$ and Private $=328$, Single $=243$ and Married $=154$ ) from different organizations of Telecom Sector. For the purpose of data collection the employees initially contacted were 475 but depending upon the rate of return and thoroughly filled, 400 questionnaires were 
sorted out as sample. Response rate of participants out of 100 was $81.33 \%$ employees and on the total 75 questionnaires were not returned. The employees who participated in the research were from information technology, engineering, accounts/finance and HR/administration department of the telecom organizations. The data were collected through purposive convenient sampling technique with participants consent.

\section{Results}

Table 1: Descriptive statistics of Participants $(\mathrm{N}=400)$

\begin{tabular}{|l|l|ll|}
\hline Variables & Categories & $\mathbf{f}$ & \% \\
\hline Gender & Male & 305 & 76.3 \\
\hline Family System & Female & 95 & 23.8 \\
\hline & oint & 232 & 58.0 \\
\hline Part Time Job Status & Nuclear & 168 & 42.0 \\
\hline & Yes & 23 & 5.8 \\
\hline Nature of Job & No & 376 & 94.0 \\
\hline & Permanent & 213 & 53.3 \\
\hline Working Sector & Contractual & 187 & 46.8 \\
\hline & Public & 71 & 17.8 \\
\hline Marital Status & Private & 328 & 82.0 \\
\hline & Single & 243 & 60.8 \\
\hline
\end{tabular}

Table 2: Pearson Product Moment Correlation between Mindfulness, Procrastination, Job Performance in employee $(\mathrm{N}=400)$

\begin{tabular}{|l|c|r|r|c|c|c|c|c|c|c|}
\hline Variable & \multicolumn{1}{|c|}{ M } & \multicolumn{1}{c|}{ SD } & \multicolumn{1}{c|}{$\alpha$} & 1 & 2 & 3 & 4 & \multicolumn{1}{c|}{5} & \multicolumn{1}{c|}{6} & \multicolumn{1}{c|}{7} \\
\hline TPS & 37.01 & 8.36 & 0.82 & - & -0.16 & -0.07 & -0.19 & -0.26 & 0.03 & 0.18 \\
\hline JP & 55.89 & 7.9 & 0.77 & - & - & 0.84 & 0.83 & 0.35 & -0.03 & -0.04 \\
\hline JPE & 28.53 & 4.88 & 0.7 & - & - & - & 0.39 & 0.35 & -0.06 & 0.01 \\
\hline JPS & 27.36 & 4.68 & 0.71 & - & - & - & - & 0.22 & 0.01 & -0.08 \\
\hline MASS & 58.98 & 12.92 & 0.87 & - & - & - & - & - & 0.06 & -0.14 \\
\hline Gender & - & - & - & - & - & - & - & - & - & 0.01 \\
\hline
\end{tabular}

${ }^{* *} \mathrm{p}<.01$

Note. MAAS $=$ Mindfulness Attention Awareness Scale, TPS $=$ Tuckman Procrastination Scale, JP = Job Performance, JP-E = Job Performance Employee, JP-S = Job Performance Supervisor

Table 2 exhibits positive correlation of mindfulness with job performance and negative with procrastination in employees. The reliability analysis revealed that alpha coefficient for mindfulness is .87procrastination is .82 and job performance is .77 which indicates alpha coefficient has satisfactory values for all variables. 
Figure 1: Marital Status as a moderator between mindfulness and job performance

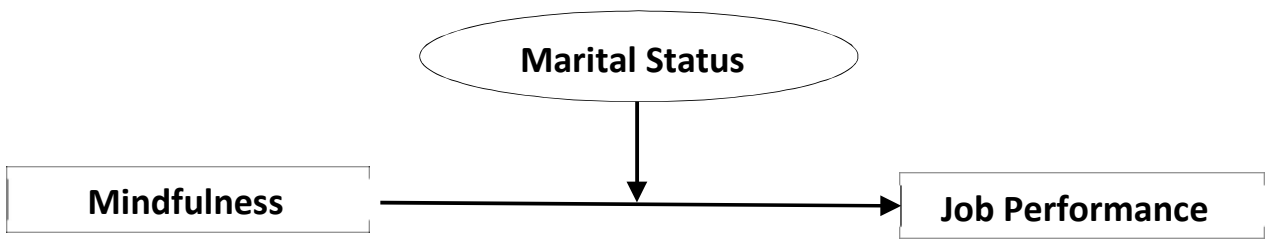

Table 3: Moderation impact of the Marital Status between Mindfulness and job performance among employees $(\mathrm{N}=400)$

\begin{tabular}{|l|c|c|r|r|r|r|r|r|}
\hline & \multirow{2}{*}{$\mathrm{R}^{2}$} & \multirow{2}{*}{$\mathrm{R}^{2}$} & \multirow{2}{*}{$\mathrm{R}^{2}$ Change/ $\Delta \mathrm{R}$} & $\mathrm{F}$ & \multicolumn{2}{|c|}{ Job Performance } & \multirow{2}{*}{$\mathrm{t}$} & $\mathrm{p}$ \\
\cline { 1 - 5 } & & & & & Coefficient & \multicolumn{1}{c|}{$\mathrm{SE}$} & & \\
\hline Model Summary & .5789 & .3352 & & 74.9461 & & & & .0000 \\
\hline Manstant & & & & & 43.1681 & 4.5387 & 9.511 & .0000 \\
\hline MASS & & & & & -8.5951 & 3.2519 & -2.6431 & .0085 \\
\hline Interaction Status & & & & & .275 & .0905 & 3.0399 & .0025 \\
\hline MASS*Marital Status & & & & & .1279 & .0637 & 1.9972 & .0464 \\
\hline
\end{tabular}

Note. MAAS $=$ Mindfulness Attention Awareness Scale

Findings revealed that moderation with marital status have been achieved significance of $\mathrm{p}<.05$ significance, which means marital status in interaction with mindfulness, has their own different and significant impact on job performance. In t-test analysis it was found that Married individuals have more mindfulness but no difference was found on overall job performance. Here interaction of predictor and moderator is suggesting its significant impact on outcome that should be clear by computing tslopes and mod-graph figure. 


\section{Figure 2:}

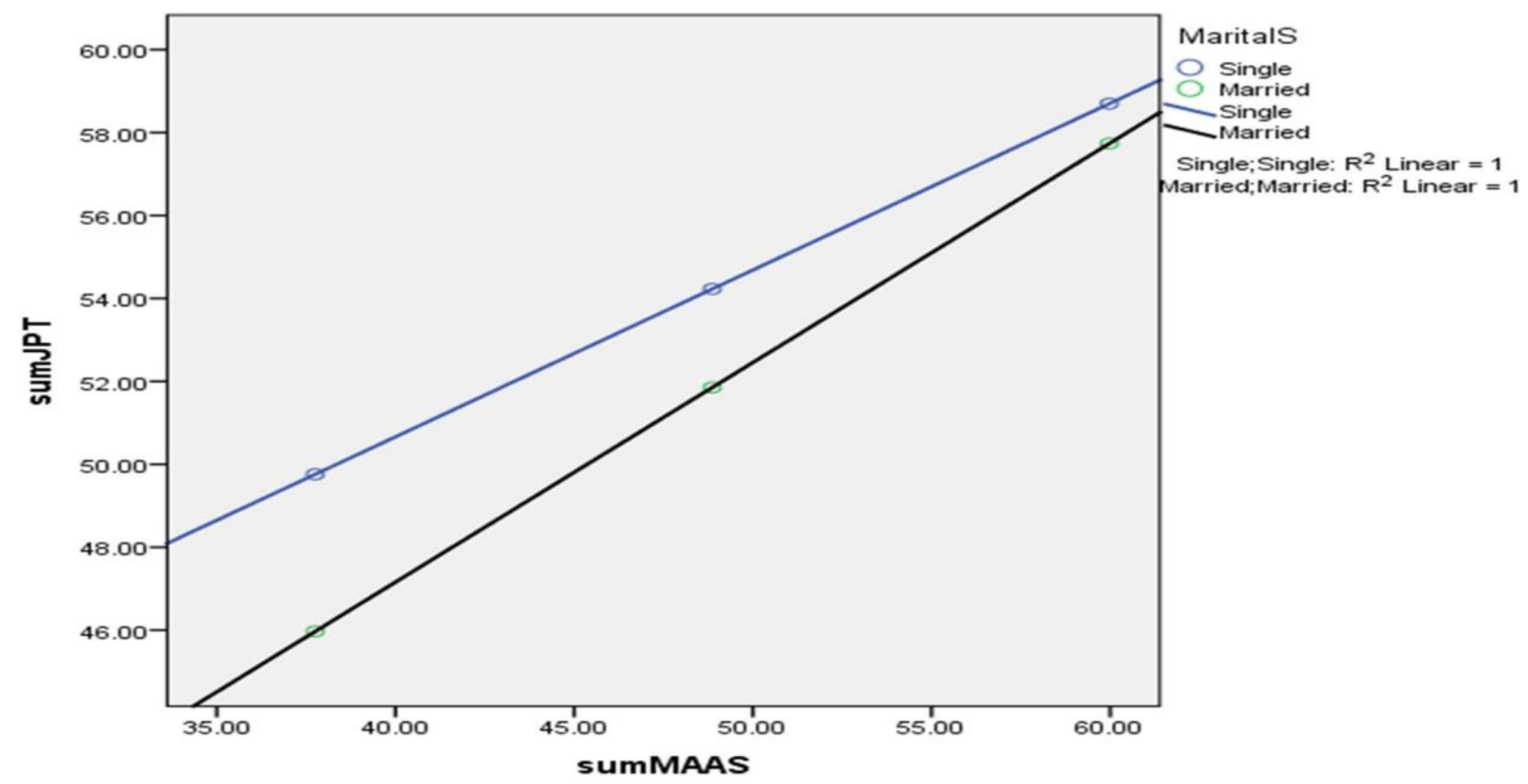

In above mod graph, single employees tend to have more mindfulness attention awareness and more job performance as compared to married employees, who have less mindfulness attention awareness and with overall less job performance.

Figure 2: Marital Status as a moderator between procrastination and job performance

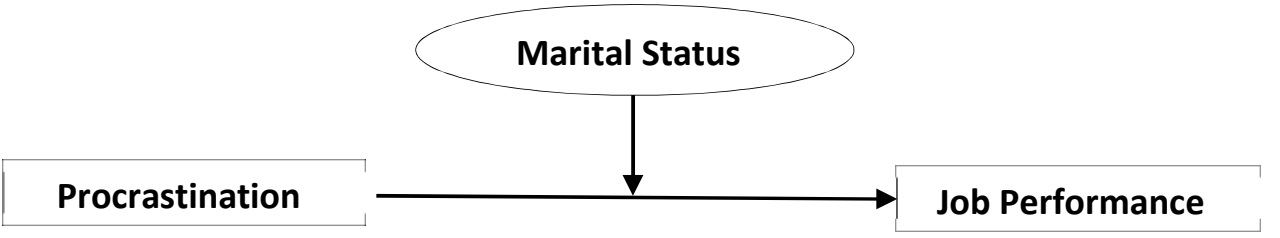

Table 4: Moderation impact of the Marital Status between procrastination and job performance among employees $(\mathrm{N}=400)$

\begin{tabular}{|l|r|r|r|r|r|r|r|r|}
\hline & \multirow{2}{*}{$\mathrm{R}^{2}$} & \multirow{2}{*}{$\mathrm{R}^{2}$} & \multirow{2}{*}{$\mathrm{R}^{2}$ Change $\Delta \mathrm{R}$} & $\mathrm{F}$ & \multicolumn{2}{|c|}{ Job Performance } & \multirow{2}{*}{$\mathrm{t}$} & \multicolumn{1}{c|}{$\mathrm{p}$} \\
\cline { 1 - 4 } & & & & .9907 & & & & .3969 \\
\hline Model Summary & .0814 & .0066 & & & 52.2728 & 5.8062 & 9.003 & .0000 \\
\hline Constant & & & & & 2.033 & 4.1725 & .4873 & .6263 \\
\hline Marital Status & & & & & .0771 & .1519 & .5072 & .6123 \\
\hline TPS & & & & & -.0869 & .1095 & -.7942 & .4275 \\
\hline Interaction & & & & & & & & .6308 \\
\hline
\end{tabular}

Note. TPS = Tuckman Procrastination Scale

Findings revealed that moderation with marital status have been achieved with no 
significance at all.

\section{Discussion}

The Job Demands-Resources (JD-R) model emphasized on employee issues related to burnout, engagement and subsequently organizational performance (Bakker \& Demerouti, 2007; Demerouti et al., 2001). The model highlighted the supposition that companies and organizations have their own issues and factors of well-being categorized as job demands and resources. Job demands factors include time pressures, a heavy workload, a stressful working environment, role ambiguity, emotional labor, and poor relationships. A Job resources factor includes physical, societal, or structural factors that assist in goal achievement and stress reduction. These factors also comprised of autonomy, work relationships, chances for progress, and training, mentoring and learning opportunities.

The model gave a comprehensive approach applicable for different occupations. Research gave indication for presence of two concurrent methods. High job demands consumed energies which lead exhaustion and impair mental and physical health. Apart from this, job resources are the motivational processes which foster employee involvement and performance at workplace. Numerous researched have found that job resources act like shield to control influences of job demands on stress-reactions. Research findings also suggested that job resources have potential to motivate specially with high job demand scenarios and help to enhance performance of employees at work. It is very obvious that when employee have resources (colleagues' support or having ability to one's own work) they tried to work beyond routine and focuses on goals and targets to accomplish (Wrzesniewski \& Dutton, 2001) on the other hand when employees having less resources at job additional performance related with their role suffer badly.

Result were found significant for marital status and relationship between mindfulness and job performance (Delta $\mathrm{R}^{2}=.005, \mathrm{~B}=.127, \mathrm{p}=.04$ ). Mod graph suggests that single (un married) employees tend to exhibit higher level of mindfulness attention awareness and enhanced job performance as compared to the married employees, who exhibit low level mindfulness attention awareness and overall a lower level of job performance. With regards to role of marital status and relationship between procrastination and job performance $(\mathrm{p}=.42)$ results appeared nonsignificant. It would be helpful to view these findings are congruent with past research; it has found that trait mindfulness is related to work-family conflict (Allen \& Kibruz, 2011). Majority of workfamily conflicts and their mitigation measures are taken by organizations for their employees. Bearing in sight that mindfulness is learnable trait, thus organizations are utilizing mindfulnessbased stress reduction techniques to develop resilience and coping skills among employees justifying the frugality and utility of mindfulness (Bishop et al., 2004; Kostanski \& Hassed, 2008).

\section{Conclusion}

These findings inhibit procrastination effects job performance of employees. Therefore, job performance could be stimulated by individual mindfulness and procrastination could decrease job performance of employees. Additionally, it recommends that the mindfulness could also enhance job performance among employees. Marital status is strong moderator among mindfulness, procrastination and job performance of employees. Results showing that single and married are performing differently. There is strong need to explore further about married employees, either their family system, number of children, marital relationship or other organizational factors which are affecting job performance and mindfulness of such employees. 
The study suggests the dire need to work on serious interventions and training programs as evidenced by researches showing that mindfulness appears to provide wide range of outcomes, ranging from reduced stress, increased focus, greater resilience, improved relationships, enhanced empathy for others, an ability to access better decision making, innovative thinking, and better health, among others. Work features like these have been instigated by professional organization who are facing performance detrimental challenges in present day work-environment (Good et al., 2016; Glomb, Duffy, Bono, \& Yang, 2011). It is hoped that this work will add to the underserved literature that seeks to provide insight into the perceptions and expectations of the facilitators of organizations as well as provide insight into the barriers that surface, and the conditions that sustenance the successful execution of mindfulness programs in organizations.

\section{References}

Afzal, S., \& Jami, H. (2018). Prevalence of academic procrastination and reasons for academic procrastination in university students. Journal of Behavioural Sciences, 28(1).

Allen, T. D. \& Kibruz, K., M. (2011). Trait mindfulness and work-family balance among working parents: The mediating effects of vitality and sleep quality Journal of Vocational Behavior, 8o(2) doi: 10.1016/j.jvb.2011.09.002

Babin, B. \& Boles, J. (1998). Employee behaviour in a service environment: a model and test of potential differences between men and women. Journal of Marketing, 62, 77-91.

Bablas, V., Yap, K., Cunnington, D., Swieca, J., \& Greenwood, K. M. (2016). Mindfulness-based stress reduction for restless legs syndrome: A proof of concept trial. Mindfulness, 7(2), 396-408.

Baer, R. A. (2003). Mindfulness training as a clinical Intervention: A conceptual and empirical review. Clinical Psychology: Science and Practice, 10, 125-143. doi: 10.1093/clipsy.bpgo15

Bartlett, L., Lovell, P., Otahal, P., \& Sanderson, K. (2017). Acceptability, feasibility, and efficacy of a workplace mindfulness program for public sector employees: a pilot randomized controlled trial with informant reports. Mindfulness, 8(3), 639-654.

Beheshtifar, M., Hoseinifar, H., \& Moghadam, M. (2011). Effect procrastination on work-related stress. European Journal of Economics, Finance and Administrative Sciences, 38, 59-64.

Brown, K. W., \& Ryan, R. M. (2003). The benefits of being present: mindfulness and its role in psychological well-being. Journal of personality and social psychology, 84(4), 822.

Bakker, A. B., \& Demerouti, E. (2007). The job demands-resources model: State of the art. Journal of managerial psychology, 22(3), 309-328.

Balkis, M. \&Duru, E.(2009).Prevalence of Academic procrastination behavior among pre-service teachers, and its relationship with demographic and individual preference. Journal of theory andpractice in education 5(1), 18- 32

Bodhi, B. (2000). The Connected Discourses of the Buddha. Wisdom Publications

Campbell, D.T. (1963). Social attitudes and other acquired behavioural dispositions. In S. Koch (Ed.), Psychology: A study of a science (Vol. 6, pp. 94-172). New York, NY: McGraw-Hill

Campbell, J. J., Dunnette, M. D., Lawler, E. E., \& Weick, K. E. (1970). Managerial behavior, performance, and effectiveness.

Canby, N. K., Cameron, I. M., Calhoun, A. T., \& Buchanan, G. M. (2015). A brief mindfulness intervention for healthy college students and its effects on psychological distress, self-control, meta-mood, and subjective vitality. Mindfulness, 6(5), 1071-1081.

Carson, S. H., \& Langer, E. J. (2006). Mindfulness and self-acceptance. Journal of rational-emotive and cognitive-behavior therapy, 24(1), 29-43.

D'Abate, C. P., \& Eddy, E. R. (2007). Engaging in personal business on the job: Extending the 
presenteeism construct. Human Resource Development Quarterly, 18(3), 361-383.

Dane, E. \& Brummel, B. J. (2013). Examining workplace mindfulness and its relations to job performance and turnover intention, Human Relations. doi: 10.1177/0018726713487753

Dane, E., \& Brummel, B. J. (2014). Examining workplace mindfulness and its relations to job performance and turnover intention. Human Relations, 67(1):105-128. doi: 10.1177/o018726713487753

Deci, E. L., \& Ryan, R. M. (1980). The empirical exploration of intrinsic motivational processes. In L. Berkowitz (Ed.), Advances in experimental social psychology (Vol. 13, pp. 39-80). New York: Academic.

Deci, Edward L.; Ryan, Richard M. (2008). Social psychology and self-determination theory: A Canadian contribution. Canadian Psychology, 49(3), 182 185. Retrieved from: http://dx.doi.o $\mathrm{rg} / 10.1037 / \mathrm{a} 0012801$

Ellis, A., \&Knaus, W. J. (1977). Overcoming procrastination. New York: Institute for Rational Living.

Evans, D. R., Baer, R. A., \& Segerstrom, S. C. (2009). The effects of mindfulness and self-consciousness on persistence. Personality and Individual Differences, 47(4), 379-382.

Falsafi, N. (2016). A randomized controlled trial of mindfulness versus yoga: effects on depression and/or anxiety in college students. Journal of the American Psychiatric Nurses Association, 22(6), 483-497.

Felleman, B. I., Stewart, D. G., Simpson, T. L., Heppner, P. S., \& Kearney, D. J. (2016). Predictors of depression and PTSD treatment response among veterans participating in mindfulness-based stress reduction. Mindfulness, 7(4), 886-895.

Ferrari, J. R., Johnson, J. L., \& McCown, W. G. (1995). Procrastination and task avoidance: Theory, research, and treatment. Springer Science \& Business Media.

Gallant, S. N. (2016). Mindfulness meditation practice and executive functioning: Breaking down the benefit. Consciousness and cognition, 40, 116-130.

Garland, E. L., \& Howard, M. O. (2013). Mindfulness-oriented recovery enhancement reduces pain attentional bias in chronic pain patients. Psychotherapy and psychosomatics, 82(5), 311-318.

Gartenschläger, M., Schreckenberger, M., Buchholz, H. G., Reiner, I., Beutel, M. E., Adler, J., \& Michal, M. (2017). Resting Brain Activity Related to Dispositional Mindfulness: a PET Study. Mindfulness, 8(4), 1009-1017.

Gagnon, J., Dionne, F., \& Pychyl, T. A. (2016). Committed action: An initial study on its association to procrastination in academic settings. Journal of Contextual Behavioral Science, 5(2), 97-102.

Gagnon, J., Dionne, F., \& Pychyl, T. A. (2016). Committed action: An initial study on its association to procrastination in academic settings. Journal of Contextual Behavioral Science, 5(2), 97-102.

Hammer, C. A., \& Ferrari, J. R. (2002). Differential incidence of procrastination between blue and white-collar workers. Current Psychology, 21(4), 333-338.

Hammer, C. A., \& Ferrari, J. R. (2002). Differential incidence of procrastination between blue and white-collar workers. Current Psychology, 21(4), 333-338.

Harpin, S. B., Rossi, A., Kim, A. K., \& Swanson, L. M. (2016). Behavioral impacts of a mindfulness pilot intervention for elementary school students. Education, 137(2), 149-156.

Hussain, I., \& Sultan, S. (2010). Analysis of procrastination among university students. Procedia-Social and Behavioral Sciences, 5, 1897-1904.

Howell, A. J., \&Buro, K. (2010). Relations among mindfulness, achievement-related self-regulation, and achievement emotions. Journal of Happiness Studies, 12(6), 1007-1022.

Klatt, M. D., Wise, E., \& Fish, M. (2012). Mindfulness and Work-Related Well-Being. Mindfulness and Buddhist-Derived Approaches in Mental Health and Addiction, Part of the series Advances in Mental Health and Addiction, 313-336

Klingsieck, K. B. (2013). Procrastination in different life-domains: Is procrastination domain 
specific?,Current Psychology, 32(2), 175-185.

Lekha Padmanabhan1 \& Dr. R. Magesh2; (2016) Difference between employee marital status and performance level in IT industry; imperial journal of interdisciplinary researchvol;02 issue;06 ISSN; 2454-1362 http:// www.onlinejournal .in

Li, G., Yuan, H., \& Zhang, W. (2016). The effects of mindfulness-based stress reduction for family caregivers: systematic review. Archives of psychiatric nursing, 30(2), 292-299.

Loucks, E. B., Britton, W. B., Howe, C. J., Eaton, C. B., \& Buka, S. L. (2015). Positive associations of dispositional mindfulness with cardiovascular health: The New England Family Study. International journal of behavioral medicine, 22(4), 540-550.

Morrison, A. B., \&Jha, A. P. (2011). Mindfulness, Attention, and Working Memory, Handbook of Mindfulness and Self-Regulation, 33-45

Morrison, A. B., Goolsarran, M., Rogers, S. L., \& Jha, A. P. (2014). Taming a wandering attention: shortform mindfulness training in student cohorts. Frontiers in Human Neuroscience, 7, 897.

Schouwenburg, H. C., Lay, C. H., Pychyl, A., \& Ferrari, J. R. (2004). Procrastination in academic settings and the Big Five model of personality: A meta-analysis. Counseling the procrastinator in academic settings, 29-40.

Schmidt, F. L., \& Hunter, J. (2004). General mental ability in the world of work: occupational attainment and job performance. Journal of personality and social psychology, 86(1), 162.

Shonin, E., Van Gordon, W., Dunn, T. J., Singh, N. N., \& Griffiths, M. D. (2014). Meditation Awareness Training (MAT) for work-related wellbeing and job performance: A randomised controlled trial. International Journal of Mental Health and Addiction, 12(6), 8o6-823.

Sirois, F. M., \& Tosti, N. (2012). Lost in the moment? An investigation of procrastination, mindfulness, and well-being. Journal of Rational-Emotive \& Cognitive-Behavior Therapy, 30(4), 237-248.

Tice, D. M., \& Bratslavsky, E. (2000). Giving in to feel good: The place of emotion regulation in the context of general self-control. Psychological inquiry, 11(3), 149-159.

Vugt, M., K., \&Jha, A. P. (2011). Investigating the impact of mindfulness meditation training on working memory: A mathematical modelling approach. Cognitive, Affective, \&Behavioural Neuroscience, 11(3), 344-353

Wrzesniewski, A., \& Dutton, J. E. (2001). Crafting a job: Revisioning employees as active crafters of their work. Academy of management review, 26(2), 179-201. 